\title{
COVID-19 in Children: Present and Future Perspective, An Interim Review
}

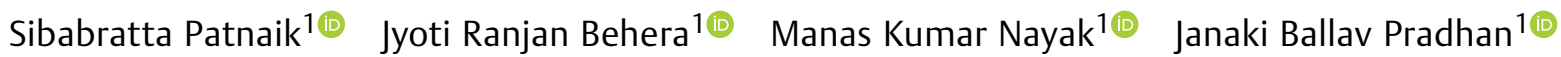 \\ Bikash Ranjan Sahu2 ${ }^{20}$ Nirmal Kumar Mohakud ${ }^{10}$
}

${ }^{1}$ Department of Pediatrics, Kalinga Institute of Medical Sciences, KIIT Deemed to be University, Bhubaneswar, Odisha, India

Address for correspondence Nirmal Kumar Mohakud, MD,

2 KIIT School of Biotechnology, KIIT Deemed to be University, Bhubaneswar, Odisha, India Department of Pediatrics, Kalinga Institute of Medical Sciences, Deemed to be University, Bhubaneswar 751024, Odisha, India (e-mail: nirmal.mahakud@kims.ac.in).

J Child Sci 2020;10:e53-e62.

\begin{abstract}
Keywords

- COVID-19

- children

- ground-glass opacity

- ACE2

- remdesivir

Coronavirus disease 2019 (COVID-19) pandemic has affected millions of people worldwide. However, the mechanism by which the pathogen affects children is not understood completely. Children so far accounted for only 1 to $6.4 \%$ of diagnosed cases and the mortality rate is also less. Though clinical findings are similar to adults, with fever and respiratory symptoms being prevalent, fewer numbers of children appear to develop severe pneumonia. Observed attenuated response to the virus may possibly be due to decrease in the expression of the angiotensin-converting enzyme 2 receptor in lungs, repeated viral exposure, and not having any underlying chronic diseases or immunosuppression. Suggested treatment included oxygen supplementation, mechanical ventilation in severe cases, nutritional support, and maintaining fluids and electrolyte balances. Although, no definitive pharmacological therapy is available, various combination of drugs like hydroxychloroquine, lopinavir/ritonavir, remdesivir, tocilizumab, and convalescent serum show promising result to an extent. As there is no specific therapeutic measure for this ailment, aggressive efforts are being made to develop a potential vaccine against the disease. Although few reports on epidemiology of COVID-19 in children have been published, comprehensive reports are lacking. The present article reviews on important issues such as epidemiological characteristics, postulations of milder disease, therapeutic aspect, and recent development of vaccination against COVID-19 in children.
\end{abstract}

\section{Introduction}

The emerging novel corona virus severe acute respiratory syndrome (SARS-CoV-2)/COVID-19 outbreak is similar to previously reported SARS (2002-2003) and Middle East respiratory syndrome (MERS; 2012) outbreaks. ${ }^{1,2}$ These three viral infections commonly present with fever, cough, and respiratory distress. The virus, SARS-CoV-2, is of a milder form in children with lower case-fatality rates as compared with adults, though the poor clinical outcomes are also associated

received

May 4, 2020

accepted

May 26, 2020
DOI https://doi.org/

10.1055/s-0040-1714113. ISSN 2474-5871. with older age and underlying comorbidities. ${ }^{3,4}$ The resistance of children to COVID-19 may be due to presence of healthy lungs and repeated exposure to different other viral pathogens that cross-protect them against COVID-19., 6

On December 31, 2019, the outbreak of COVID-19 was first noticed in Wuhan city, Hubei province, China, in few adults who presented with pneumonia of unexplained etiology, ${ }^{7,8}$ and World Health Organization (WHO) declared the disease as pandemic on March 11, 2019. ${ }^{9}$ Aggressive research efforts are 


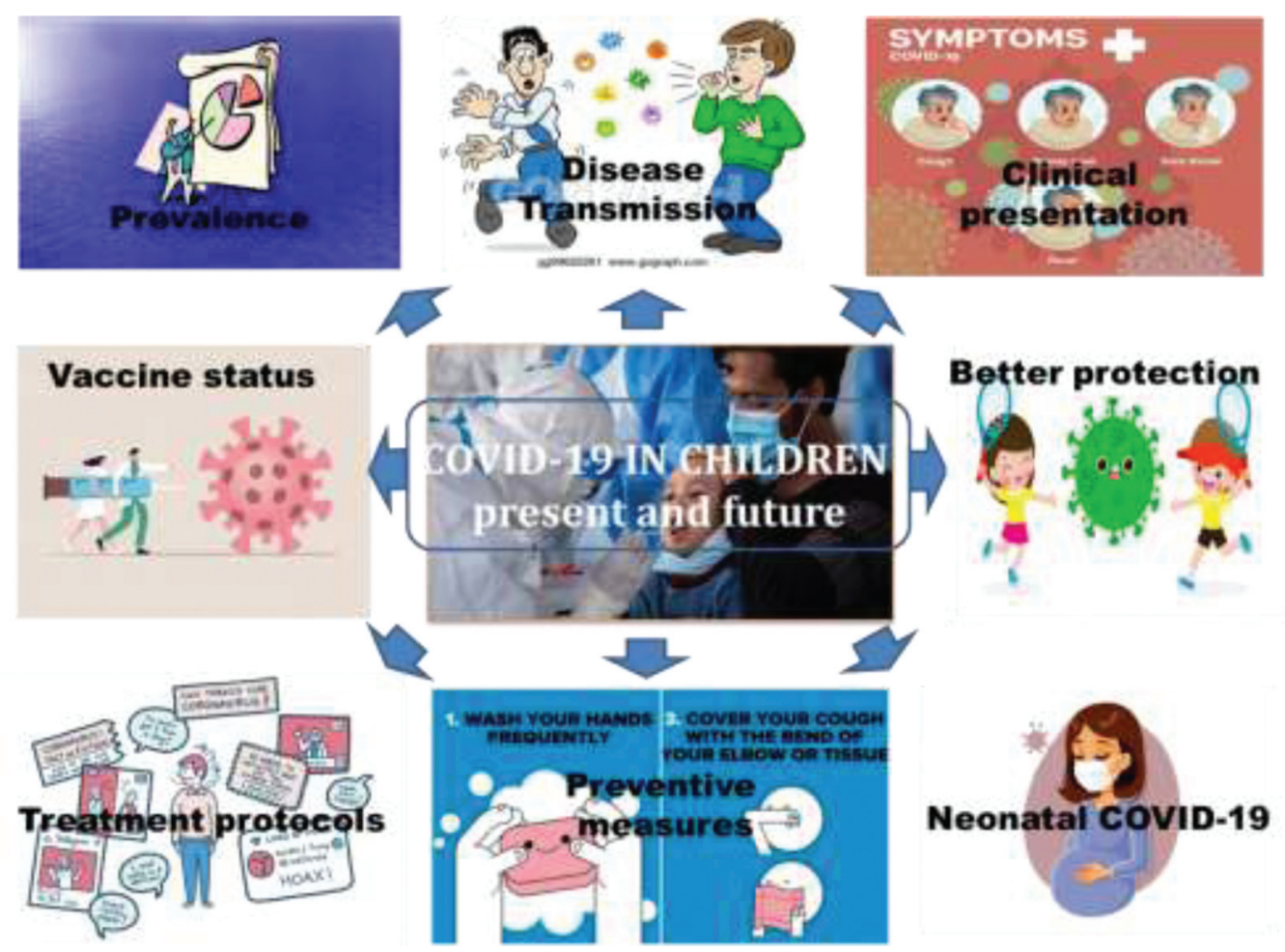

Fig. 1 Promising areas of research on COVID-19 in children.

currently going on to regulate this new SARS-CoV-2 outbreak in terms of therapeutic measures and vaccine development. Many numbers of review articles have been published in the last several months on different scientific aspects of the disease in relation to adults, as a relatively higher frequency of this population gets affected in comparison to children. However, discussion on aspects such as etiology, mode of transmission, unique clinical parameters, possible diagnostic approaches, and treatment protocols are less known in children. This gap prompted us to summarize these aspects in this interim review (-Fig. 1). Additionally, we also outlined the current status of vaccine development against COVID-19 that are under clinical trials.

\section{Prevalence of COVID-19 in Children}

Till date, COVID-19 has spread to 213 countries and territories worldwide and 2 international conveyances affecting 5.2 million people and 334,000 of death (https://www. worldometers.info/coronavirus/?, accessed 22 May 2020). The incidence of the disease in children varies from 1 to $6.4 \%$ in different countries. ${ }^{10-13}$ The disease is prevalent among all age groups of children including newborns; however, evidence of vertical transmission are rare. ${ }^{14,15} \mathrm{Al}$ though no significant difference in prevalence between genders was observed in the study, few studies reported slightly higher incidence in boys than girls. ${ }^{16,17}$

Only $1.3 \%$ of the screened children were found positive as compared with $3.5 \%$ of adults who had history of contact with infection positive cases. The virus was persistently found in the rectal swabs of few children even after it has cleared from nose and throat swabs. But it is not clear if the virus particles in the feces are infectious. ${ }^{18}$

Prior study suggested that only 112 (5.6\%) of 2,143 children developed severe disease (defined as hypoxia), whereas only $13(0.6 \%)$ children developed respiratory problem, multiorgan failure, or acute respiratory distress syndrome (ARDS). ${ }^{17}$ Overall case-fatality rate in adults varies between 2.3 (China) and 7.2\% (Italy), with an average of $4 \%$ globally. ${ }^{10,19,20}$ However, the case-fatality rate in children up to 19 years is only $0.9 \%{ }^{19}$

\section{Transmission and Pathophysiology}

According to speculations, SARS-CoV-2 was first detected in bats followed by transmission to pangolins. In Wuhan seafood market, China, humans became accidental hosts after being infected through pangolins, and human-to-human transmission of COVID-19 started in this city. ${ }^{16}$ The virus is highly contagious, propagates easily from person-to-person specially at overcrowded areas. The major modes of transmission include droplets and fomites followed by airborne transmission. ${ }^{21}$ The mean incubation time is 2 to 14 days with an average incubation time of 8 days ${ }^{22}$; however, other studies reported incubation period of up to 3 weeks. ${ }^{22,23}$ The cause of infection positive cases reported after 30 to 40 days of incubation is most likely due to the asymptomatic nature of the disease and not due to prolonged incubation period. The transmission rate/reproduction number (R0) (defined as the number of individuals who can get infected by a single person carrying the virus) is estimated between 2.2 and 3.6, which is comparable to SARS but the 
values are higher than MERS. ${ }^{24}$ The viability of the virus varies from hours in aerosol to days on solid surfaces. ${ }^{25}$

The protein S1 of SARS-CoV-2 facilitates the entry of the pathogen into target host cells after binding with the transmembrane angiotensin-converting enzyme 2 (ACE2) receptor and mediates pathogenesis. The virus mostly attacks the lungs, gastrointestinal system, and myocardial and hepatic cells, where the ACE2 is adequately present. ${ }^{26}$ The pathogenic mechanisms are mostly cytokine and chemokine mediated.

\section{Cytokine Storm}

The central mechanism of pathogenesis in severe cases is a "cytokine storm." It has been proved that delayed release of cytokines and chemokines occurs in respiratory epithelial cells, dendritic cells, and macrophages at the early stage of SARS-CoV-2 infection. Later, the cells secrete low levels of the antiviral factors interferons (IFNs) and high levels of proinflammatory cytokines interleukin (IL)-1 $\beta$, IL-6, tumor necrosis factor (TNF), and chemokines (C-C motif chemokine ligand $[C C L]-2, C C L-3$, and CCL-5). The production of IFN-I or IFN- $\alpha / \beta$ is the key natural immune defense response against viral infections. High levels of expression of IL-1 $\beta$, IFN- $\gamma$, IFN- $\gamma-$ induced protein 10 (IP-10), and monocyte chemoattractant protein 1 have been detected in patients with COVID-19. Delayed release of IFNs in the early stages of infection slows the hosts' antiviral response. Afterwards, the rapidly increased cytokines and chemokines attract many inflammatory cells, such as neutrophils and monocytes, etc., resulting in excessive infiltration of the inflammatory cells causing tissue destruction, and thus lung injury leading to ARDS. ${ }^{27}$

\section{ARDS Types}

Gattinoni et al have proposed two different phenotypes of ARDS, the L and H; Type L is characterized by low elastance (i.e., high compliance), low ventilation-to-perfusion ratio, low lung weight, and low recruitability, and Type $\mathrm{H}$ is characterized by high elastance, high right-to-left shunt, high lung weight, and high recruitability. ${ }^{28}$

\section{Extrapulmonary Manifestation}

The extrapulmonary manifestations are due to expression of ACE2 receptor on cells of other organs. In liver, virus-induced cytopathic effects leads to liver injury ranging from 14.8 to $78 \%$ of infected cases, mainly presenting with abnormal levels of alanine aminotransferase (ALT) and aspartate aminotransferase accompanied by slightly elevated bilirubin levels. ${ }^{29}$ Nausea or vomiting, or both, and diarrhea were reported as gastrointestinal manifestations. Adult patients with COVID-19 may experience cardiac injury and arrhythmia; however, these symptoms are infrequently reported in children, but renal failure was found in one child. ${ }^{30}$

\section{Significance of Lymphopenia}

Several factors may contribute to COVID-19-associated lymphopenia. Lymphocytes express the ACE2 receptor on their surface; therefore, SARS-CoV-2 may directly infect those cells and ultimately lead to their lysis. Furthermore, the cytokine storm causing markedly elevated levels of ILs and
TNF- $\alpha$, may promote lymphocyte apoptosis. The cytokine activation may be associated with atrophy of lymphoid organs, including the spleen, and can further impair lymphocyte turnover. Coexisting lactic acid acidosis, may also inhibit lymphocyte proliferation. Decreased lymphopenia in children may be again due to immaturity and less ACE2 receptor in children. ${ }^{31}$

\section{Clinical Presentation}

The clinical symptoms include typical of acute respiratory infections such as fever (32-50\%), ${ }^{17,18}$ cough (48-83\%), ${ }^{17,32}$ sore throat $(46-73 \%),{ }^{17,32}$ diarrhea $(8.8 \%)$, fatigue $(7.6 \%)$, rhinorrhoea (7.6\%), and vomiting (6.4\%). ${ }^{30}$ Other features such as sneezing and myalgia were also reported. ${ }^{33,34}$ It was found that few children did not demonstrate any symptoms or abnormal radiological finding. ${ }^{32}$ Recently, other clinical presentations such as repeated shivering with chills, muscle pain, headache, conjunctivitis, sore throat, and loss of smell or taste have been noted (https://www.cdc.gov/coronavirus/ 2019-ncov/symptoms-testing/symptoms.html). Few cases had presentation such as hyperinflammatory shock, showing features similar to a typical Kawasaki disease, Kawasaki disease shock syndrome, or toxic shock syndrome, and development of small pleural, pericardial, and ascitic effusions, suggestive of a diffuse inflammatory process. ${ }^{35}$

The children, especially of adolescent age group, may undergo severe anxiety and depression during this pandemic and may also have suicidal tendencies due to fear of the disease or may be due to loss of a dear one of COVID-19. So it is of immense importance to understand the bereavement process to prevent these unwanted psychological conditions. ${ }^{36,37}$

Reports have revealed that, 3 to $5 \%$ of children may suffer with severe illness in various geographical areas. ${ }^{17,38}$ Tachycardia was observed in $42 \%$ children on admission making it the most common sign of the disease, followed by tachypnea observed in $28 \%$ of patients. Another study showed mortality of 1 child and only 3 children (1.7\%) requiring mechanical ventilation due to their comorbidities. ${ }^{32}$

\section{Why is COVID-19 Mild in Children?-Possible Postulations}

Several hypotheses on possible mechanism for milder effect of the disease in children have been postulated. They are outlined as follows:

1. Underestimation of exact burden of the disease due to undertesting for COVID-19, as children are mostly asymptomatic.

2. Children suffer from several viral infections and such repeated viral exposure might have supported the immune system when it reacts to SARS-CoV-2. ${ }^{5,6,39}$

3. SARS-CoV-2 infects the human cells through the interaction of $S$ (spike) protein to ACE2 receptor on cells. ${ }^{40}$ Presence of immature form of receptors and/or different configuration causes an improper binding of virus to the receptor imposing lesser effect in the host. ${ }^{16}$ 
4. The immature immune system in children may induce reduced inflammation in children. However, severe cases of children demonstrating high levels of procalcitonin and IL-6 have also been reported. ${ }^{41}$

5. Prior study indicated lymphocytopenia in 914 (83.2\%) of adults versus $9(0.82 \%)$ of children. ${ }^{16}$ Therefore, it is assumed that lymphocytopenia may be associated with severity of disease and children are less sufferers.

6. Less severe infection in children may be attributed to the presence of a healthier lungs as compared with adults, as adults have been exposed to pollution (environmental pollution and smoking) over a period of time.

7. The immune system of children and adults differs both in structural and functional aspect. ${ }^{42}$

8. Children show fewer outdoor activities as compared with adults and undertake less international travel, therefore, making them less likely to get infected with the virus.

\section{Diagnostic Approach of COVID-19 in Children}

Who should test for the disease?

1. Any child who demonstrates features of severe acute respiratory infection should undergo testing for presence of infection.

2. Children with a history of contact with confirmed or suspected cases within 14 days prior to disease onset.

3. Newborns delivered by suspected or confirmed SARSCoV-2-infected mothers.

\section{Confirmed Cases}

The cases will be considered as confirmed for COVID-19 infection if suspected cases meet one of the following criteria $^{43}$

1. Throat swab, sputum, or blood samples tested positive for SARS-CoV-2 using real-time polymerase chain reaction (RT-PCR).

2. Genome sequencing of throat swab, sputum, or blood samples showing high degree of homology with known SARS-CoV-2.

3. Granules of SARS-CoV-2 isolated by culture from throat swab, sputum, or blood samples.

RT-PCR is the robust and commonly implemented method all over the world. Viral gene sequencing is cumbersome and expensive, while virus culture cannot be performed in all laboratories

Normal or reduction in total white blood cell count and lymphocytopenia may be observed rarely in children. Creactive protein and procalcitonin level are usually increased. Elevation of liver enzymes (lactate dehydrogenase, ALT), muscle enzymes, myoglobin, and D-dimer may be seen in severe cases. CPK-MB level is also increased in most of the cases. Raised ferritin may be suggestive of bad prognosis. Consistent pattern of characteristic laboratory findings has not been established in children.

Imaging Analysis

On X-ray, appearance of multiple patchy shadows and interstitial changes indicates the onset of disease. ${ }^{44}$ Severe cases can further develop to bilateral multiple ground-glass opacity, infiltrating shadows, and pulmonary consolidation with infrequent pleural effusion. ${ }^{45}$ In computed tomography (CT) chest, the most common findings are bilateral peripheral and subpleural ground-glass or consolidative opacities often in the lower lobes of the lungs. The "halo" sign, that describes a focal consolidation with a rim of surrounding ground-glass opacity, has been reported in up to $50 \%$ of cases. Three phases of evolution have been observed in pediatric COVID-19 cases: the "halo" sign is generally observed early in the disease course and progresses to ground-glass and finally develops into consolidative opacities. Peribronchial thickening and inflammation along the bronchovascular bundle are observed more frequently in the pediatric population compared with adults. Fine mesh reticulations and "crazy paving" sign have also been reported. Pleural effusion and lymphadenopathy are rarely found. ${ }^{46}$

CT of chest is shown in - Fig. 2. Fig. 2A shows scattered ground-glass opacities in the inferior lobe of the right lung. Fig. 2B shows left lung consolidation and surrounded by ground-glass opacities. Fig. 2C shows diffused consolidations and ground-glass opacities in both lungs, with a "white lung" appearance of the right lung (CT, chest of 14,10 , and 1 year children). ${ }^{34}$

\section{Vertical Transmission and Neonatal COVID-19}

The prevalence of COVID-19 in neonates is not known. Potential vertical transmission (prenatal/perinatal) of SARS-CoV-2 from infected pregnant women to newborns is uncertain. The body fluids, such as respiratory secretions and saliva, contain SARS-CoV-2, however, the pathogen is not detected in blood and stool in nonpregnant women with severe illness. ${ }^{47}$ The studies conducted in China did not detect any virus in maternal whole blood, serum, vaginal mucus, amniotic fluid, and/or breast milk, but maternal nasopharyngeal specimens were found to contain viruses. ${ }^{14,48-50}$ Two studies describe the detection of SARS-CoV2-specific immunoglobulin (Ig) M and IgG in three newborns of infected women, suggesting the possibility of transplacental transfer triggering the IgM antibody production in the fetus, ${ }^{51,52}$ but like other diseases false-positive IgM results limit its interpretation and we need further studies to confirm the possibility of in utero transmission. ${ }^{53}$

\section{Breastfeeding Practice with COVID-19 Mothers}

Breast milk provides protection against many illnesses and it is the best source of nutrition for most infants. The limited evidence till now shows that virus does not pass through the breast milk from an infected mother with SARS-CoV-2. ${ }^{44}$ As per the Centers for Disease Control and Prevention recommendations, mothers should be encouraged to express their breast milk after adequate hand hygiene either by manual hand expression or through breast pump to establish and maintain milk supply during temporary separation (https://www.cdc. gov/coronavirus/2019-ncov/prepare/pregnancy-breastfeeding. html) and a healthy caregiver will feed the expressed breast 


\section{Computed Tomography,chest of 14,10 and 1 year children}

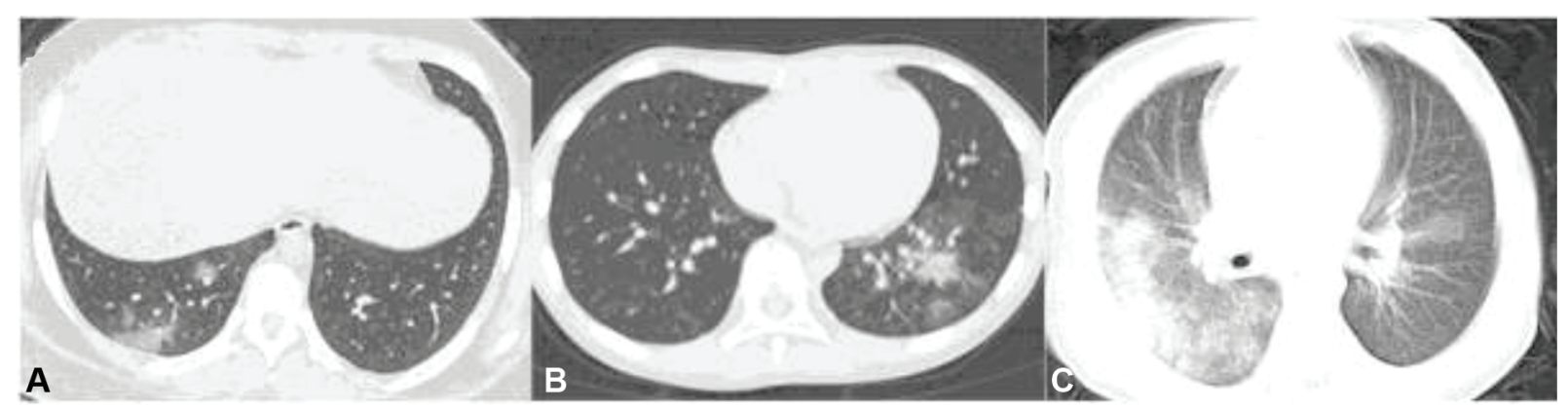

Taken from-Pediatr Pulmonol . John Wiley \& Sons, Ltd; 2020; http://dx.doi.org/10.1002/ppul.247180

Fig. 2 Computed tomography, chest of 14,10, and 1 year children. Taken from: Pediatr Pulmonol. John Wiley \& Sons, Ltd; 2020; http://dx.doi. org/10.1002/ppul.247180.

milk in the isolated room. If parents wish for room-in and the mother wants to feed the baby directly from breast, she should put on a face mask and practice hand hygiene before each feeding.

\section{Treatment Protocol}

There is no definitive treatment for COVID-19 per se. Management consists of supportive treatment and use of drugs that may have antiviral activity. The multiple randomized clinical trials with different drug formulations performed in different countries may provide some fruitful information soon. Vast majority of children do not require any therapy; however, those who have higher risk for bad outcome may get benefit from early antiviral therapy. Few drug formulations for possible treatment of COVID-19 are described in the following sections.

\section{Chloroquine and Hydroxychloroquine}

These are antimalarial agents widely used in India and are found to show antiviral property. ${ }^{54}$ These agents interfere with cellular receptor ACE2, and impair acidification of endosome, which interferes with virus trafficking within the cell.

These drugs have immunomodulatory action as well, suppressing the release of TNF and IL-6 and act as a novel class of autophagy inhibitors and thus interfere with viral infection and replication. They interfere with glycosylation of cellular receptor SARS-CoV-2. Therapeutic trial for chloroquine and azithromycin in combination was performed in France and it was found to be effective in eliminating the virus. ${ }^{55}$ However, in the latest observational study involving 1,446 patients with COVID-19 who had been admitted to the hospital, hydroxychloroquine (HCQ) administration was not associated with either a greatly lowered or an increased risk of the composite endpoint of intubation or death. Random clinical trials (RCTs) may throw more light on this. ${ }^{56}$ Recommended dosage: infants and children: oral HCQ 3 to $5 \mathrm{mg} / \mathrm{kg} /$ day (max dose $400 \mathrm{mg}$ ) twice a day for 5 days. $^{57}$

\section{Remdesivir}

Many in vitro studies on action of this drug have shown encouraging results. ${ }^{58,59}$ Remdesivir acts on NSP12 polymerase enzyme and was found to be effective for a patient in United States. Currently, the drug is under clinical trial in the United States and other countries. The results were found that remdesivir performed better on the primary endpoint of "time to recovery" when compared with placebo. The median time to recovery was 11 versus 15 days, respectively.

\section{Lopinavir/Ritonavir (Kaletra)}

The combination of lopinavir/ritonavir is mainly used as an anti-human immunodeficiency virus agent. ${ }^{60}$ Lopinavir is a protease inhibitor and ritonavir reduces metabolism of lopinavir by acting as cytochrome P-3A inhibitor. ${ }^{54}$ Reports from Korea and Singapore have shown positive results on efficacy of these agents. ${ }^{61,62}$ However, in a RCT by Cao et al, two study groups, with and without the drugs, showed similar viral decay at the end of therapy indicating the ineffectiveness of the drugs. ${ }^{63}$ Further study is required to examine the efficacy of the drug. In a recent phase 2 trial study, early triple antiviral therapy (lopinavir/ritonavir, ribavirin, and IFN $\beta-1 b$ ) was safe and superior as compared to lopinavir-ritonavir alone in alleviating symptoms and shortening the duration of viral shedding and hospital stay in patients with mild to moderate COVID-19. ${ }^{64}$

Recommended dosage: Based on weight: Less than $15 \mathrm{~kg}$ : $12 \mathrm{mg} / \mathrm{kg} /$ dose (lopinavir component) orally twice a day; 15 to $40 \mathrm{~kg}$ : $10 \mathrm{mg} / \mathrm{kg} /$ dose (lopinavir component) orally twice a day; greater than $40 \mathrm{~kg}$ : lopinavir/ritonavir $2 \times 200 / 50 \mathrm{mg}$ tablet, orally twice a day. It can be given for 5 to14 days, depending on physician's judgment.

\section{Corticosteroids}

Recent Infectious Disease Society of America guidelines also suggest against use of steroids in COVID-19 pneumonia. Early administration of glucocorticoids inhibits the initiation of the body's immune defense mechanism, thereby increasing the viral load and ultimately leading to adverse consequences. Therefore, glucocorticoids are primarily used in critically ill 
patients suffering from inflammatory cytokine storm. ${ }^{65} \mathrm{~A}$ short course treatment of methylprednisolone 1 to $2 \mathrm{mg} / \mathrm{kg} /$ day for 3 to 5 days is advised in the sicker population of COVID19 with ARDS. ${ }^{66}$

\section{Convalescent Serum}

Passive antibody in convalescent serum can cause viral neutralization. Possible mechanisms include antibody-dependent cytotoxicity and/or phagocytosis. ${ }^{67}$ Convalescent serum was used in five COVID-19 patients with ARDS. However, no definite statement could be given due to inadequate sample size. ${ }^{68}$ There are reports for use of specific intravenous immunoglobulins (IVIGs) in which the specific convalescent IVIG is purified from sera of convalescing patients and can be used in minimum amount. ${ }^{69}$

\section{Tocilizumab}

Tocilizumab is an IL-6 inhibitor, which is one of the major cytokines. There is a risk of severe infection (bacterial, invasive fungal, viral, and tubercular) in patients receiving tocilizumab. Xu et al treated 21 cases of severe and critical COVID-19 patients with tocilizumab and did not find any death in those patients. However, this study had no control group. $^{70}$ Dose: $<30 \mathrm{~kg}$ : $12 \mathrm{mg} / \mathrm{kg}$; $>30 \mathrm{~kg}$ : $8 \mathrm{mg} / \mathrm{kg}$ ( $\max$ $800 \mathrm{mg} /$ dose), one dose only. Inhalational therapy with IFN- $\alpha$ b had been tried by few and found to reduce the level of IL-6, thus opened the ways for further RCTs. ${ }^{71}$

Although many numbers of clinical trials on drugs are going on, owing to lack of effective antiviral therapy, currently supportive and symptomatic treatment is the main stay of management. Oxygen delivered by different methods, including by high-flow nasal cannula (HFNC) is very useful. Gattinoni et al has proposed that COVID-19 pneumonia type L will benefit from HFNC, continuous positive airway pressure, or noninvasive ventilation, and if they require invasive ventilation, they should not be given very high positive endexpiratory pressure (PEEP). However, if the disease progresses to type $\mathrm{H}$, it should be treated as severe ARDS, including high PEEP. ${ }^{28}$ Proning can be done as a recruitment maneuver. Awake proning was found to be helpful in a series from Jiangsu province. ${ }^{72}$ All patients with COVID-19 should be managed with conservative fluid approach.

\section{Current Vaccine Strategies for COVID-19}

As a preventive strategy, it is undoubtedly essential to develop safe and highly efficacious vaccines to control the COVID-19 pandemic and ultimately prevent the future recurrence of the disease. Despite persistent efforts made by different scientific communities, no significant success has been achieved in developing an appropriate vaccine against COVID-19. Most of the vaccines target the surface-exposed spike glycoprotein or S protein that elicits neutralizing antibodies. Several S protein-based strategies have been attempted for developing CoV vaccines, for example, use of full-length $\mathrm{S}$ protein or S1-receptor-binding domain and expression in virus-like particles, deoxyribonucleic acid, or viral vectors. ${ }^{73-75}$
Among different vaccine formulations, six of them are among front runners that have entered into clinical trials (summarized in - Table $\mathbf{1}$ ).

1. CanSino Biologics and The Academy of Military Medical Sciences, China, have developed a vaccine formulation that contains a nonreplicating adenovirus (Ad5) vector carrying the gene for SARS-CoV-2 spike protein. The preclinical testing with Ad5-nCoV vaccine revealed a strong immune response in animal models and has shown a good safety profile. The phase I clinical trial is underway in China (https://www.the-scientist.com/news-opinion/ covid-19-vaccine-frontrunners-67382).

2. The University of Oxford, United Kingdom, developed an efficacious vaccine that contains chimpanzee adenovirus vaccine vector (ChAdOx1) carrying the gene for the SARS$\mathrm{CoV}-2$ spike protein. Although, no preclinical testing is done by this company on this vaccine, prior study suggested that this vector (ChAdOx1) carrying a gene for MERS demonstrated a significant titer of neutralizing antibodies and cellular immune response in mice against MERS-CoV. ${ }^{76}$ A phase I/II single-blinded, randomized, placebo-controlled, multicenter studies are underway to determine the efficacy, safety, and immunogenicity of ChAdOx1-nCoV-19 in U.K. healthy adult volunteers aged 18 to 55 years (https://clinicaltrials.gov/ct2/show/ NCT04324606).

3. Another novel vaccine formulation was developed by Moderna, USA that has lipid nanoparticles containing messenger ribonucleic acids (mRNAs) for the SARSCoV-2 spike protein (SARS-CoV-2-mRNA 1273). A phase 1 , open-label clinical trial in both males and nonpregnant females (aged 18-55 years) has been designed to test the safety and reactogenicity of the vaccine (https:// clinicaltrials.gov/ct2/show/NCT04283461).

4. PiCoVacc, an emerging candidate vaccine developed recently by Sinovac, China, has successfully finished the preclinical trials. It was found that macaques injected with a dose of this potential vaccine were completely protected against the virus after challenge. It raises a big hope among scientists for its efficacy against humans and clinical trials are underway (https://www.deccanherald.com/science-and-environment/rescued-sloth-bears-undergo-successful-dental-procedures-in-bengaluru-837148.html).

5. Pfizer, USA, and its German partner BioNtech have begun clinical trials of vaccine candidate BNT162 with 360 healthy volunteers. The vaccine is based on a specially designed mRNA and claimed to induce neutralizing antibodies in experimental animal models. Results are still awaited (https://www.pfizer.com/news/press-release/press-releasedetail/pfizer_and_biontech_dose_first_participants_in_the u_s_as_part_of_global_covid_19_mrna_vaccine_development_program).

6. INO-4800, the vaccine formulation developed by Inovio Pharmaceuticals, a biotechnology company in Pennsylvania, United States, is ready for its phase I clinical trial with 40 volunteers to test the tolerability and reactogenicity (https://clinicaltrials.gov/ct2/show/results/NCT04336410). 


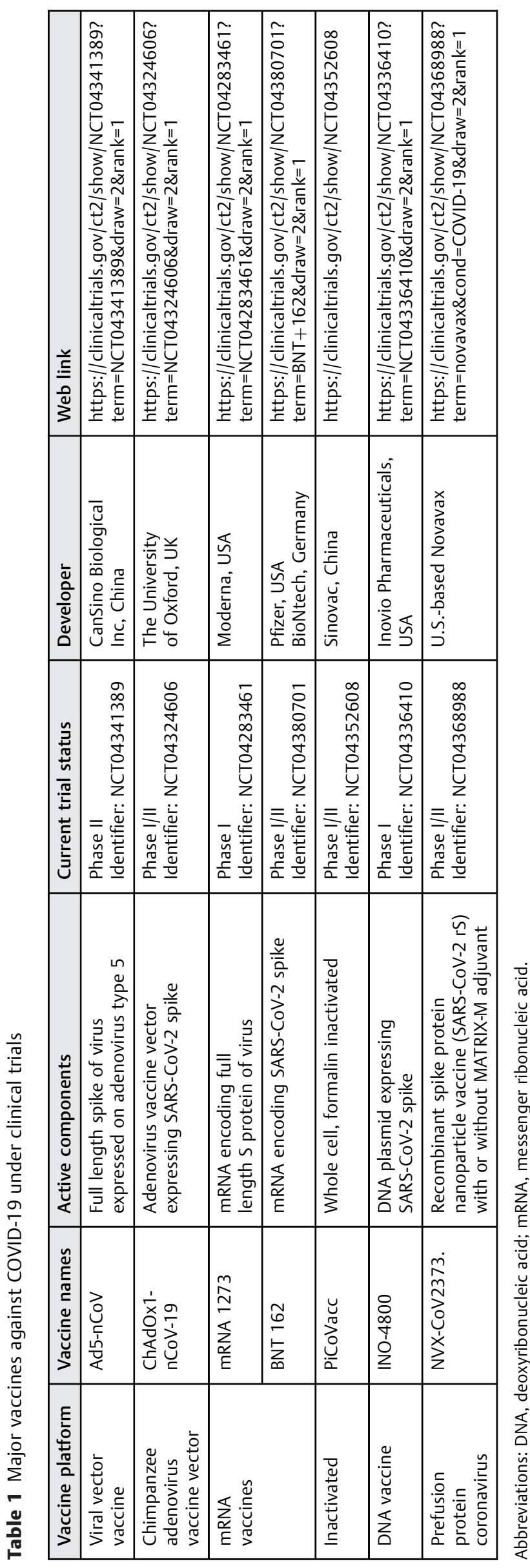

Multiple countries are now working to examine if the Bacillus Calmette-Guerin (BCG) live-attenuated vaccine candidate can confer protection against SARS-nCoV. All trials are in phase II/III; however, results are yet to be published (https:// www.pharmaceutical-technology.com/comment/bcg-vaccination-covid-19/). BCG vaccines are supposed to induce metabolic and epigenetic changes that enhance the innate immune response to subsequent infections, a process termed trained immunity which might therefore reduce viremia after SARSCOV-2 exposure. Interestingly, countries with a national program of whole population BCG vaccination appear to show lower incidence and death rate from COVID-19 as compared with those where BCG vaccination is not mandatory. ${ }^{77}$ The findings from the study suggesting less COVID-19, in countries with routine BCG immunization is weak on evidence because it is based on individual data and is prone to confounding. Moreover, a large population-based cohort from Israel does not support the idea that BCG vaccination in childhood has a protective effect against COVID-19 in adulthood. ${ }^{78}$ But more clinical trials of this vaccine are underway, to know the protective efficacy against the disease.

Moreover, the Strategic Advisory Group of Experts on immunization recommended that all mass vaccination campaigns should be discontinued but routine immunization should continue where possible. ${ }^{79}$ Besides these 6 candidate vaccines, there are more than 40 vaccine formulations designed by different scientific organizations worldwide that are in preclinical stage of development (according to WHO). We are not including details on these vaccines in the current review due to paucity of exact information of animal testing data.

\section{Preventive Measures}

Hands should be thoroughly cleaned with alcohol-based hand rub or should be washed with soap and water to kill the virus. Social distancing should be maintained by at least 3 feet. Eyes, nose, and mouth should not be touched with hands to prevent entry of the virus into the body. Importantly, respiratory hygiene should be practiced by covering mouth and nose with bent elbow or tissue while coughing and sneezing. "Stay at home" is the best practice to prevent infection and quarantine of contacts as early as possible is the key to success to prevent nosocomial spread. ${ }^{1,80}$

\section{Future Perspectives}

The SARS-CoV-2 raging around the world showed a tendency to tread gently with children. This is a boon to infants and children as they seem to be protected. However, critical cases have also been noticed in many parts of the world as mentioned in this review. Therefore, the strategies for diagnosis, treatment, and prevention from COVID-19 should also be considered seriously for children, in addition to adults. Further, a need for point-of-care diagnostic device for quick detection of the virus is also essential. Many RCTs are going on presently to get the wonder molecule against the virus. Above all, since prevention is always better than cure, there is a great demand for a highly immunogenic vaccine formulation 
against this disease that can be effectively administered to children to provide long-term protective immunity.

Limitation of the report is that we have not analyzed the pediatric papers in a systematic way due to paucity of data. Also, as the situation is still emerging, new data are appearing almost daily. However, we have included all studies from Asia, Europe, and the United States for complete updation.

\section{Conclusion}

Children at all ages are susceptible to COVID-19. The infection rate as well as mortality rate is relatively low among children due to the different immune mechanism than adults. Household contact is the main source of infection causing disease in the children. Though the disease is relatively milder in children, they may play a major role in community-based viral transmission. Prolonged shedding in nasal secretions has substantial implications for community spread in daycare centers, schools, and home. The main strategy for control of disease will be infection control and to stop community and nosocomial spread. As there is no specific treatment for COVID-19 at present, the future research should be directed toward making an effective vaccine and detecting an appropriate molecule to counter it.

\section{Authors' Contributions}

S.P., J.B., and N.M. developed the idea and concept. M.N. and J.P. conducted literature search and review. N.M., B.S., and S. P. drafted the manuscript and provided critical review. All authors read and approved the final manuscript for submission. The manuscript has been read and approved by all the authors and N.K.M. will correspond on behalf of all.

\section{Funding}

None.

\section{Conflict of Interest}

None declared.

\section{Acknowledgments}

We thank Dr. Mirabai Das and Master Nabendu Mohakud for technical support in preparing the manuscript.

\section{References}

1 Anderson RM, Fraser C, Ghani AC, et al. Epidemiology, transmission dynamics and control of SARS: the 2002-2003 epidemic. Philos Trans R Soc Lond B Biol Sci 2004;359(1447):1091-1105

2 Ramadan N, Shaib H. Middle East respiratory syndrome coronavirus (MERS-CoV): a review. Germs 2019;9(01):35-42

3 Zimmermann P, Curtis N. Coronavirus infections in children including COVID-19: an overview of the epidemiology, clinical features, diagnosis, treatment and prevention options in children. Pediatr Infect Dis J 2020;39(05):355-368

4 Hon KL, Leung CW, Cheng WT, et al. Clinical presentations and outcome of severe acute respiratory syndrome in children. Lancet 2003;361(9370):1701-1703

5 Nickbakhsh S, Mair C, Matthews L, et al. Virus-virus interactions impact the population dynamics of influenza and the common cold. Proc Natl Acad Sci U S A 2019;116(52):27142-27150
6 Heimdal I, Moe N, Krokstad S, et al. Human coronavirus in hospitalized children with respiratory tract infections: a 9-year population-based study from Norway. J Infect Dis 2019;219(08): 1198-1206

7 Lu H, Stratton CW, Tang YW. The Wuhan SARS-CoV-2-what's next for China. J Med Virol 2020. Doi: 10.1002/jmv.25738

8 Zhang S, Diao MY, Duan L, Lin Z, Chen D. The novel coronavirus (SARS-CoV-2) infections in China: prevention, control and challenges. Intensive Care Med 2020;46(04):591-593

9 Cucinotta D, Vanelli M. WHO declares COVID-19 a pandemic. Acta Biomed 2020;91(01):157-160

10 Novel CP; Epidemiology Working Group for NCIP Epidemic Response, Chinese Center for Disease Control and Prevention. The epidemiological characteristics of an outbreak of 2019 novel coronavirus diseases (COVID-19) in China [in Chinese]. Zhonghua Liu Xing Bing Xue Za Zhi 2020;41(02):145-151

11 Shim E, Tariq A, Choi W, Lee Y, Chowell G. Transmission potential and severity of COVID-19 in South Korea. Int J Infect Dis 2020; 93:339-344

12 Livingston E, Bucher K. Coronavirus disease 2019 (COVID-19) in Italy. JAMA 2020;323(14):1335-1335

13 CDC COVID-19 Response Team. Severe outcomes among patients with coronavirus disease 2019 (COVID-19) - United States, February 12-March 16, 2020. MMWR Morb Mortal Wkly Rep 2020; 69(12):343-346

14 Chen H, Guo J, Wang C, et al. Clinical characteristics and intrauterine vertical transmission potential of COVID-19 infection in nine pregnant women: a retrospective review of medical records. Lancet 2020;395(10226):809-815

15 Schwartz DA. An analysis of 38 pregnant women with COVID-19, their newborn infants, and maternal-fetal transmission of SARS CoV-2:maternal corona virus infections and pregnancy outcomes. Arch Pathol Lab Med 2020;144(07):799-805

16 Guan WJ, Ni ZY, Hu Y, et al; China Medical Treatment Expert Group for Covid-19. Clinical characteristics of coronavirus disease 2019 in China. N Engl J Med 2020;382(18):1708-1720

17 Dong Y, Mo X, Hu Y, et al. Epidemiological characteristics of 2143 pediatric patients with 2019 coronavirus disease in China. Pediatrics 2020 (forth coming). Doi:10.1542/peds.2020-0702

$18 \mathrm{Xu}$ Y, Li X, Zhu B, et al. Characteristics of pediatric SARS-CoV-2 infection and potential evidence for persistent fecal viral shedding. Nat Med 2020;26(04):502-505

19 Onder G, Rezza G, Brusaferro S. Case-fatality rate and characteristics of patients dying in relation to COVID-19 in Italy. JAMA 2020

20 Sinha IP, Harwood R, Semple MG, et al. COVID-19 infection in children. Lancet Respir Med 2020;8(05):446-447

21 Ozma MA, Maroufi P, Khodadadi E, et al. Clinical manifestation, diagnosis, prevention and control of SARS-CoV-2 (COVID-19) during the outbreak period. Infez Med 2020;28(02):153-165

22 Lauer SA, Grantz KH, Bi Q et al. The incubation period of coronavirus disease 2019 (COVID-19) from publicly reported confirmed cases: estimation and application. Ann Intern Med 2020;172(09):577-582

23 Leung C. The difference in the incubation period of 2019 novel coronavirus (SARS-CoV-2) infection between travelers to Hubei and nontravelers: the need for a longer quarantine period. Infect Control Hosp Epidemiol 2020;41(05):594-596

24 Li Q, Guan X, Wu P, et al. Early transmission dynamics in Wuhan, China, of novel coronavirus-infected pneumonia. N Engl J Med 2020;382(13):1199-1207

25 van Doremalen N, Bushmaker T, Morris DH, et al. Aerosol and surface stability of SARS-CoV-2 as compared with SARS-CoV-1. N Engl J Med 2020;382(16):1564-1567

26 Li W, Moore MJ, Vasilieva N, et al. Angiotensin-converting enzyme 2 is a functional receptor for the SARS coronavirus. Nature 2003; 426(6965):450-454

27 Mehta P, McAuley DF, Brown M, Sanchez E, Tattersall RS, Manson JJ; HLH Across Speciality Collaboration, UK. COVID-19: consider 
cytokine storm syndromes and immunosuppression. Lancet 2020;395(10229):1033-1034

28 Gattinoni L, Chiumello D, Caironi P, et al. COVID-19 pneumonia: different respiratory treatments for different phenotypes? Intensive Care Med 2020:1

29 Musa S. Hepatic and gastrointestinal involvement in coronavirus disease 2019 (COVID-19): what do we know till now? [Internet] Arab J Gastroenterol 2020;21(01):3-8

30 Ludvigsson JF. Systematic review of COVID-19 in children shows milder cases and a better prognosis than adults. Acta Paediatr 2020;109(06):1088-1095

31 Terpos E, Ntanasis-Stathopoulos I, Elalamy I, et al. Hematological findings and complications of COVID-19. Am J Hematol 2020

32 Lu X, Zhang L, Du H, et al; Chinese Pediatric Novel Coronavirus Study Team. SARS-CoV-2 infection in children. N Engl J Med 2020; 382(17):1663-1665

33 Dong Y, Mo X, Hu Y, et al. Epidemiology of COVID-19 among children in China. Pediatrics 2020:e20200702

34 Xia W, Shao J. Clinical and CT features in pediatric patients with COVID - 19 infection: different points from adults. Pediatr Pulmonol [Internet] 2020:1-6

35 Riphagen S, Gomez X, Gonzalez-martinez C, Wilkinson N, Theocharis P. Correspondence hyperinflammatory shock in children during. Lancet 2020;6736:2019-2020

36 Pompili M, Shrivastava A, Serafini G, et al. Bereavement after the suicide of a significant other. Indian J Psychiatry 2013;55(03):256-263

37 Pompili M, Gibiino S, Innamorati M, et al. Prolactin and thyroid hormone levels are associated with suicide attempts in psychiatric patients. Psychiatry Res 2012;200(2-3):389-394

38 Wang Z, Zhou Q, Wang C, et al. Clinical characteristics of children with COVID-19: a rapid review and meta-analysis. Med Rxiv 2020;x:1-41

39 Liu Y, Yan L, Wan L, et al. Correspondence and severe cases of. Lancet Infect Dis 2020;201:2019-2020

40 Wrapp D, Wang N, Corbett KS, et al. Cryo-EM structure of the 2019-nCoV spike in the . prefusion conformation. Science 2020; 367(6483):1260-1263

41 Henry BM, Lippi G, Plebani M. Laboratory abnormalities in children with novel coronavirus disease 2019. Clin Chem Lab Med 2020;58(07):1135-1138

42 Simon AK, Hollander GA, McMichael A. Evolution of the immune system in humans from infancy to old age. Proceedings of the Royal Society B: Biological Sciences. 2015 December 22282 (1821):20143085

43 Chen ZM, Fu JF, Shu Q et al. Diagnosis and treatment recommendations for pediatric respiratory infection caused by the 2019 novel coronavirus. World J Pediatr 2020; $\cdots \bullet: 1-7$

44 Huang C, Wang Y, Li X, et al. Clinical features of patients infected with 2019 novel coronavirus in Wuhan, China. Lancet 2020;395 (10223):497-506

45 Chan JFW, Yuan S, Kok KH, et al. A familial cluster of pneumonia associated with the 2019 novel coronavirus indicating person-toperson transmission: a study of a family cluster. Lancet 2020;395 (10223):514-523

46 Foust AM, Phillips GS, Chu WC, et al. International expert consensus statement on chest imaging in pediatric COVID-19 patient management: imaging findings, imaging study reporting and imaging study recommendations. Radiol. Cardiothoracic Imaging. 2020;2(02):e200214

47 Chen W, Lan Y, Yuan X, et al. Detectable 2019-nCoV viral RNA in blood is a strong indicator for the further clinical severity. Emerg Microbes Infect 2020;9(01):469-473

48 Chen W, Lan Y, Yuan X, et al. Detectable 2019-nCoV viral RNA in blood is a strong indicator for the further clinical severity. Emerg Microbes Infect 2020;9(01):469-473

49 Wang X, Zhou Z, Zhang J, Zhu F, Tang Y, Shen X. A case of 2019 novel coronavirus in a pregnant woman with preterm delivery. Clin Infect Dis 2020:ciaa200
50 Wang S, Guo L, Chen L, et al. A case report of neonatal COVID-19 infection in China. Clin Infect Dis 2020:ciaa225

51 Zeng H, Xu C, Fan J, et al. Antibodies in infants born to mothers with COVID-19 pneumonia. JAMA 2020

52 Dong L, Tian J, He S, et al. Possible vertical transmission of SARSCoV-2 from an infected mother to her newborn. JAMA 2020; Doi: 10.1001/jama.2020.4621 [Internet]

53 Kimberlin DW, Stagno S. Can SARS-CoV-2 infection be acquired in utero?: more definitive evidence is needed JAMA 2020

54 Guo YR, Cao QD, Hong ZS, et al. The origin, transmission and clinical therapies on coronavirus disease 2019 (COVID-19) outbreak - an update on the status. Mil Med Res 2020;7(01):11

55 Gautret P, Lagier JC, Parola P, et al. Hydroxychloroquine and azithromycin as a treatment of COVID-19: results of an openlabel non-randomized clinical trial. Int J Antimicrob Agents 2020; c.o: 105949

56 Geleris J, Sun Y, Platt J, et al. Observational Study of Hydroxychloroquine in Hospitalized Patients with Covid-19. N Engl J Med 2020 Doi: 10.1056/NEJMoa2012410

57 Karimi A, Tabatabaei SR, Rajabnejad M, et al. An algorithmic approach to diagnosis and treatment of coronavirus disease 2019 (COVID-19) in children: Iranian expert's consensus statement. Arch Pediatr Infect Dis. 2020;8(02):e102400

58 Sheahan TP, Sims AC, Leist SR, et al. Comparative therapeutic efficacy of remdesivir and combination lopinavir, ritonavir, and interferon beta against MERS-CoV. Nat Commun 2020;11(01): 222

59 Holshue ML, DeBolt C, Lindquist S, et al; Washington State 2019nCoV Case Investigation Team. First case of 2019 novel coronavirus in the United States. N Engl J Med 2020;382(10):929-936

60 Cvetkovic RS, Goa KL. Lopinavir/ritonavir: a review of its use in the management of HIV infection. Drugs 2003;63(08):769-802

$61 \mathrm{Lim}$ J, Jeon S, Shin HY, et al. Case of the index patient who caused tertiary transmission of COVID-19 infection in Korea: the application of lopinavir/ritonavir for the treatment of COVID-19 infected pneumonia monitored by quantitative RT-PCR. J Korean Med Sci 2020;35(06):e79

62 Arabi YM, Alothman A, Balkhy HH, et al; And the MIRACLE trial group. Treatment of Middle East respiratory syndrome with a combination of lopinavir-ritonavir and interferon- $\beta 1 \mathrm{~b}$ (MIRACLE trial): study protocol for a randomized controlled trial. Trials 2018;19(01):81

63 Cao B, Wang Y, Wen D, et al. A trial of lopinavir-ritonavir in adults hospitalized with severe Covid-19. N Engl J Med 2020;382(19): 1787-1799

64 Hung IF, Lung KC, Tso EY, et al. Triple combination of interferon beta- $1 \mathrm{~b}$, lopinavir-ritonavir, and ribavirin in the treatment of patients admitted to hospital with COVID-19: an open-label, randomised, phase 2 trial. Lancet 2020:S0140-6736(20)31042-4

65 Ye $\mathrm{Q}$, Wang $\mathrm{B}$, Mao J. The pathogenesis and treatment of the 'Cytokine Storm' in COVID-19. J Infect 2020;80(06):607-613

66 Alhazzani W, Møller MH, Arabi YM, et al. Surviving Sepsis Campaign: guidelines on the management of critically ill adults with coronavirus disease 2019 (COVID-19). Intensive Care Med 2020;46(05):854-887

67 Casadevall A, Pirofski LA. The convalescent sera option for containing COVID-19. J Clin Invest 2020;130(04):1545-1548

68 Shen C, Wang Z, Zhao F, et al. Treatment of 5 critically ill patients with COVID-19 with convalescent plasma. JAMA 2020;323(16): 1582-1589

69 Shoenfeld Y. Corona (COVID-19) time musings: our involvement in COVID-19 pathogenesis, diagnosis, treatment and vaccine planning. Autoimmun Rev 2020;19(06):102538

$70 \mathrm{Xu} \mathrm{X}$, Han M, Li T, et al. Effective treatment of severe COVID-19 patients with tocilizumab. Proceedings of the National Academy of Sciences; 2020 April 29

71 Zhou Q Wei XS, Xiang X, et al. Interferon-a2b treatment for COVID-19. MedRxiv 2020. Doi: 10.1101/2020.04.06.20042580 
72 Care I, Sun Q, Qiu H, Huang M, Yang Y. Lower mortality of COVID - 19 by early recognition and intervention : experience from Jiangsu Province. Ann Intensive Care. 2020;2-5;. Doi: 10.1186/s13613-020-00650-2

73 Yang ZY, Kong WP, Huang Y, et al. A DNA vaccine induces SARS coronavirus neutralization and protective immunity in mice. Nature 2004;428(6982):561-564

74 Jiang S, He Y, Liu S. SARS vaccine development. Emerg Infect Dis 2005;11(07):1016-1020

75 Wrapp D, Wang N, Corbett KS, et al. Cryo-EM structure of the 2019-nCoV spike in the prefusion conformation. Science 2020; 367(6483):1260-1263

76 Alharbi NK, Padron-Regalado E, Thompson CP, et al. ChAdOx1 and MVA based vaccine candidates against MERS-CoV elicit neutral- ising antibodies and cellular immune responses in mice. Vaccine 2017;35(30):3780-3788

77 Hegarty PK, Kamat AM, Zafirakis H, Dinardo A. BCG vaccination may be protective against Covid-19. Preprint 2020

78 Hamiel U, Kozer E, Youngster I. SARS-CoV-2 rates in BCG-vaccinated and unvaccinated young adults. JAMA 2020; Doi: 10.1001/ jama.2020.8189

79 World Health Organization. Guiding principles for immunization activities during the COVID-19 pandemic: interim guidance, 26 March 2020. World Health Organization; 2020

80 Leung TF, Ng PC, Cheng FW, et al. Infection control for SARS in a tertiary paediatric centre in Hong Kong. J Hosp Infect 2004;56 (03):215-222 